\title{
Исследование пористой структуры активного угля из рисовой шелухи
}

\author{
Тху Аунг Си ${ }^{1}$, Вин Мьинт Со ${ }^{1}$, Клушин В.Н. ${ }^{1}$, Нистратов А.В. ${ }^{1}$, \\ Киреев С.Г. ${ }^{2}$, Мухин В.M. ${ }^{2}$ \\ ${ }^{1}$ РХТУ им. Д.И. Менделеева, Москва \\ ${ }^{2}$ ОАО ЭНПО «Неорганика», Электросталь МО
}

Поступила в редакцию 19.09.2016 г.

\begin{abstract}
Методом низкотемпературной адсорбции азота исследована пористая структура активного угля из рисовой шелухи. Установлено, что при парогазовой активации первичная пористость карбонизата, представленная ультрамикропорами с максимумом при $\sim 0.68$ нм, супермикропорами с максимумом $\sim 1.1$ нм и мезопорами с максимумом $\sim 3$ нм, развивается в направлении радиального выгорания ультрамикропор со смещением максимума распределения в сторону увеличения размеров, полного выгорания супермикропор и двукратным ростом объема мезопор.
\end{abstract}

Ключевые слова: карбонизат, активный уголь, изотерма, адсорбция, десорбция, гистерезис, микропоры, объем сорбционного пространства.

\section{Investigation of porous structure of activated carbon from rice husks}

\author{
Thu Aung $\mathrm{Si}^{1}$, Win Myint Saw ${ }^{1}$, Klushin V.N. ${ }^{1}$, Nistratov A.V. ${ }^{1}$, \\ Kireev S.G. ${ }^{2}$, Mukhin V.M. ${ }^{2}$ \\ ${ }^{1}$ Mendeleev University of chemical technology of Russia, Moscow \\ ${ }^{2} J S C$ «ENPO «Neorganika», Elektrostal
}

\begin{abstract}
of Myanmar is their processing into activated carbons by method of carbonization and activation with water vapor. Characteristic changes of porous structure of the carbonized husks at the processing by water vapour at $800^{\circ} \mathrm{C}$ for 0,25 hours, were estimated by the method of low-temperature nitrogen adsorption, the results of which are processed according to the Dubinin-Radushkevich equation. Analysis of the isotherms of adsorption-desorption of carbonization and activation products indicates, that at activation capable of chemisorption acid centers on surface of the material partly disappear, and its primary and secondary porous structure changes significantly. In particular, sorbing pores of the carbonizate, represented by ultramicro-, supermicroand mesopores with distribution peaks of $0.68,1.1$ and $3 \mathrm{~nm}$ respectively, burn out in radial direction and enlarge in size, forming micro- and mesopores. The differences of behaviour at activation at the same conditions between the carbonizate of rice husks and that of coconut shells, forming predominantly micropores, are shown. A significant (28\% of the volume of sorbing pores) proportion of mesopores in activated carbon from rice husks predetermines feasibility of its use in processes of gas purification, that is illustrated by absorption of n-butanol from its air-steam mixtures. The study of the kinetics and equilibrium of this process by using a spring scale shows the benefits of activated carbon from rice husk compared to activated carbon, producted from coconut shells: a higher adsorption capacity $(145 \mathrm{mg} / \mathrm{g})$ and less time of its achievement. Alternative estimation of the volume of sorbing pores of these adsorbents by benzene vapor gives smaller volume of sorbing pores due to unavailability of ultramicropores for molecules of adsorbate.
\end{abstract}

Keywords: carbonizate, activated carbon, isotherm, adsorption, desorption, hysteresis, micropores, volume of sorption space. 


\section{Введение}

Ранее нами было показано, что при получении активного угля из скорлупы кокосового ореха методом парогазовой активации первичная пористость карбонизата эволюционирует как в сторону уменьшения размеров микропор, так и с образованием мезопор [1]. Цель настоящей работы состояла в исследовании изменения пористой структуры при приготовлении активного угля из рисовой шелухи на основании экспериментальных данных, полученных при низкотемпературной адсорбции азота.

\section{Эксперимент}

В качестве объектов исследования в настоящей работе использованы активный уголь из рисовой шелухи (АУР), полученный при парогазовой активации его прекурсора - карбонизата рисовой шелухи (КР). Условия получения КР - нагрев воздушно-сухой рисовой шелухи с интенсивностью $15^{\circ} \mathrm{C} /$ мин. до $650^{\circ} \mathrm{C}$ с выдержкой при этой температуре в течение 30 мин и последующее остывание в изолированном реакторе до комнатной температуры. При производстве АУР полученный КР нагревали с той же интенсивностью до $800^{\circ} \mathrm{C}$ при подаче водяного пара с удельным расходом около 7 кг на 1 кг АУР и термообработкой при $800^{\circ} \mathrm{C}$ в течение 0.25 часа.

Адсорбционные измерения были выполнены при температуре 77К на автоматической адсорбционной установке ASAP-2020 фирмы Micromeritics, тренировку образцов проводили при температуре $300^{\circ} \mathrm{C}$ в течение 6 часов при давлении менее 1 Па.

Для характеристики пористой структуры сорбентов использовали общепринятую в научной практике модель Дубинина-Радушкевича, на основании которой рассчитывали параметры пористой структуры сорбентов [объем микропор $\left(\mathrm{V}_{\text {ми }}\right)$, объем мезопор $\left(\mathrm{V}_{\text {ме }}\right)$, объем сорбционного пространства $\left(\mathrm{V}_{\text {ми+ме }}\right)$, энергия адсорбции $\left.\left(\mathrm{E}_{\mathrm{a}}\right)\right]$, а также теорию функционала плотности (DFT), расчетный аппарат которой дает возможность оценить распределение пор по размерам [2]. Объем сорбционного пространства по бензолу $\left(\mathrm{W}^{\mathrm{S}}\right)$ определяли эксикаторным методом [3].

Кинетика и равновесие адсорбции паров н-бутанола из его смесей с воздухом АУР и использованным для сопоставления активным углем, полученным из скорлупы кокосовых орехов [1], изучены в проточном трубчатом стеклянном реакторе с пружинными весами [4], показания которых фиксировали катетометром КМ-6.

\section{Обсуждение результатов}

Изотермы сорбции азота на объектах исследования, представленные на рис. 1, согласно классификации БДТТ могут быть охарактеризованы по внешнему виду как занимающие промежуточное положение между первым и четвертым структурными типами [5]. Следует отметить, что при наличии явно выраженного гистерезиса отклонение десорбционной ветви от адсорбционной в точке завершения гистерезиса (при $\mathrm{p} / \mathrm{p}_{\mathrm{o}}=0.24$ ) наблюдается как для КР, так и для АУР и составляет 3.2 и $1.3 \mathrm{~cm}^{3} / \Gamma$ НТД соответственно.

Согласно общепринятым представлениям, в условиях адсорбционного опыта, принятых в настоящей работе, происходит, как правило, физическая адсорбция, при которой адсорбат адсорбируется на всех участках поверхности адсорбента вне зависимости от их химической природы [6]. Исключением является случай наличия кислотных центров, способных к взаимодействию с молекулой азота, обладающего

Txy Аунг Си и др. / Сорбционные и хроматографические процессы. 2017. Т. 17. № 1 
квадрупольным моментом [2]. Таким образом, необратимое связывание молекул адсорбата может быть обусловлено наличием хемосорбционного канала вследствие присутствия кислотных центров на поверхности сорбентов, причем при переходе от КР к АУР этот канал подавляется на $80 \%$, в то время как для кокосового активного угля, исследованного в работе [1], такие кислотные центры полностью заблокированы, и в точке завершения гистерезиса адсорбционная и десорбционная ветви соответствующей изотермы совпадают.

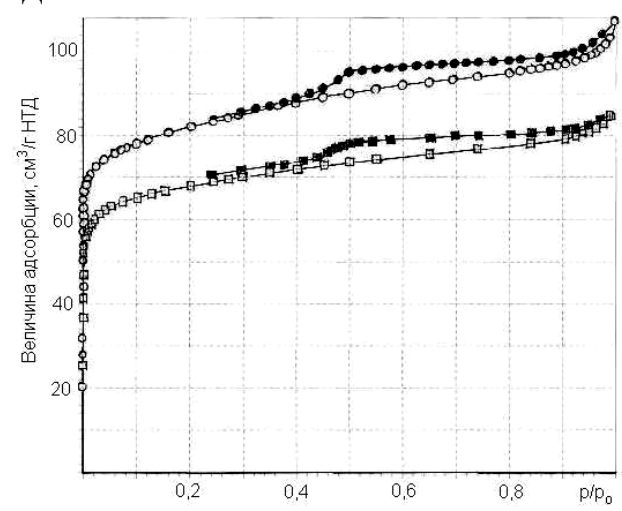

Рис. 1. Адсорбция азота при 77К:

а: (口) - КР адсорбция, (•) - КР десорбция; (०) - АУР адсорбция, (•) - АУР десорбция

Другое отличие объектов исследвания настоящей работы от таковых, рассмотренных в работе [1], заключается в большем вкладе гистерезиса в сорбционный процесс. Так, если для кокосового угля высота петли гистерезиса при $\mathrm{p} / \mathrm{p}_{0}=0.5$ составляет $4.2 \%$ от емкости монослоя, а для его карбонизата гистерезис отсутствует, то для АУР и КР высота петли гистерезиса при таком же относительном давлении уже составляет 11.7 и 12.2\% от емкости монослоя, соответственно. Несмотря на несущественное различие в численном значении этой величины для АУР и КР изотерма для активного угля имеет следующие отличия: во-первых, при малых и больших заполнениях, например, при $\mathrm{p} / \mathrm{p}_{0}=0.05$ и $\mathrm{p} / \mathrm{p}_{0}=0.90$, соответственно, разница в величинах адсорбции составляет 52\%. Во-вторых, при приближении к $\mathrm{p} / \mathrm{p}_{0}=1$ наблюдается более крутой подъем. Это может указывать на отличие первичной и вторичной супрамолекулярной структуры объектов.

Действительно, приведенные на рис. 2 кривые распределения пор по размерам наглядно подтверждают изменения пористой структуры карбонизата, представленной ультрамикропорами с максимумом при $\sim 0.68$ нм, супермикропорами с максимумом $\sim 1.1$ нм и мезопорами с максимумом $\sim 3$ нм, в процессе его активации.

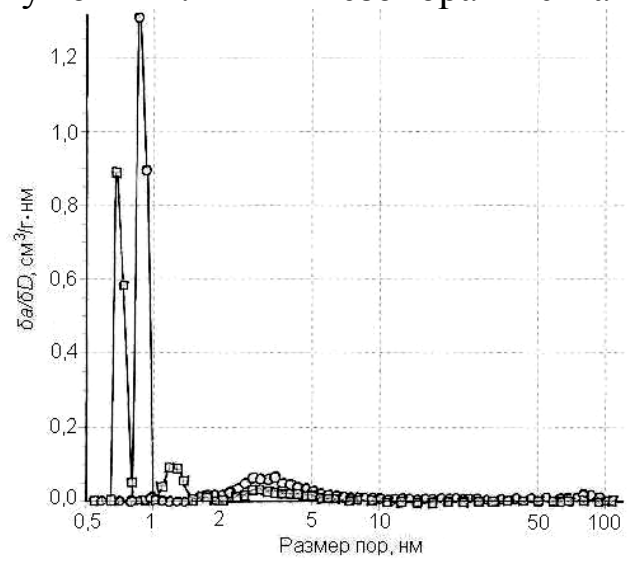

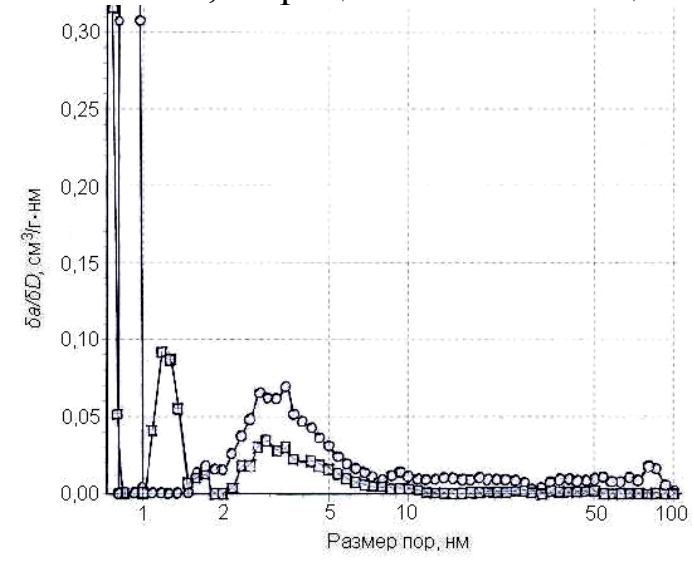

6

Рис. 2. Распределение пор по размерам. Обозначения как на рис. 1

$\boldsymbol{T} x y$ Аунг Си и др. / Сорбционные и хроматографические процессы. 2017. Т. 17. № 1 
При переходе от КР к АУР величина максимума первого пика возрастает в полтора раза и пик смещается в область супермикропор, а пик с максимумом $1.1 \mathrm{Hм}$, характеризующий супермикропоры в КР, на кривой распределения АУР отсутствует. Это может быть интерпретировано как увеличение размера пор, обусловленное выгоранием микропор в радиальном направлении в процессе парогазовой активации. В этом отличие объектов исследования настоящей работы от таковых, рассмотренных в работе [1], где для кокосового угля обнаружено смещение максимумов в сторону меньших размеров, что было приписано эффекту возникновения и развития новых пор в массе карбонизованного материала в процессе его активации.

Кроме того, наблюдается развитие мезопор практически во всем расчетном интервале от 3 до 100 нм. Логично полагать, что приведенные на рис. 2а и рис. 2б результаты носят только оценочный характер, но для характеристики тенденции развития пористой структуры могут считаться пригодными.

Экспериментальные данные удовлетворительно описываются в рамках модели Дубинина-Радушкевича. Результаты расчетов представлены в табл. 1.

Таблица 1. Характеристика пористой структуры карбонизата и активного угля

\begin{tabular}{|c|c|c|c|c|c|}
\hline \multirow{2}{*}{ Образец } & \multicolumn{3}{|c|}{ Объем пор, $\mathrm{cm}^{3} / \Gamma$} & \multirow{2}{*}{ Еа, кДж/моль } & $\begin{array}{c}\mathrm{W}^{\mathrm{S}}, \mathrm{cm}^{3} / \Gamma \\
\left(\text { по } \mathrm{C}_{6} \mathrm{H}_{6}\right)\end{array}$ \\
\cline { 2 - 5 } & $\mathrm{Vми}+\mathrm{Me}$ & $\mathrm{Vми}$ & $\mathrm{V}$ ме & 20.8 & 0.099 \\
$\mathrm{KУ}$ & 0.132 & 0.107 & 0.025 & 27.5 & 0.157 \\
\hline
\end{tabular}

По сравнению с кокосовым углем [1], имеющим долю мезопор 0.13 от сорбционного объема, доля мезопор АУР составляет уже 0.28 от сорбционного объема, что может обусловливать перспективность его применения в сорбционных процессах в динамических условиях. В пользу этого свидетельствуют данные, представленные на рис. 3-5, полученные с использованием зерен (частиц) фракции 2-4 мм обоих углей при поглощении ими при $20^{\circ} \mathrm{C}$ паров н-бутанола из его смесей с воздухом и указывающие на существенные преимущества кинетического и равновесного плана АУР по сравнению с активным углем, полученным в работе [1] из скорлупы кокосового ореха.

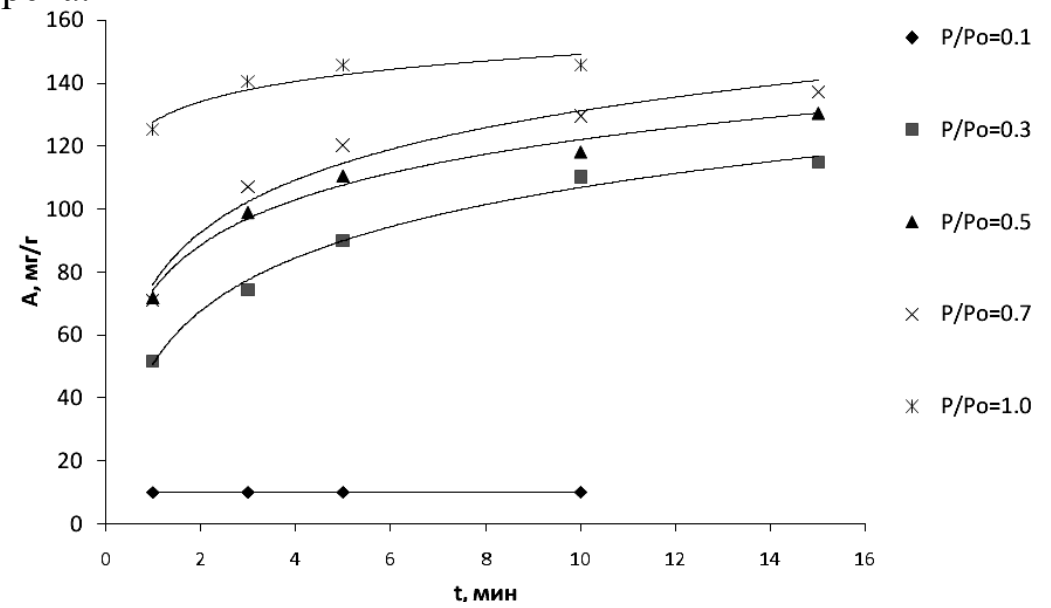

Рис. 3. Кинетика адсорбции бутанола на активном угле из рисовой шелухи

Превышение величин сорбционного объема по азоту по сравнению с таковым по бензолу, можно объяснить гораздо меньшим размером молекулы азота и обусловленной этим фактом возможностью заполнения пор субмолекулярных размеров, недоступных для молекулы более крупного по размерам адсорбата - бензола. При этом следует обратить внимание на то, что указанное превышение для кокосового 
угля [1] составляет $20 \%$, для АУР - $5.7 \%$, тогда как для КР - $33.3 \%$. Этот факт может служить подтверждением гораздо большего выгорания и, соответственно, увеличения размеров пор субмолекулярных размеров в случае АУР, чем для кокосового угля.

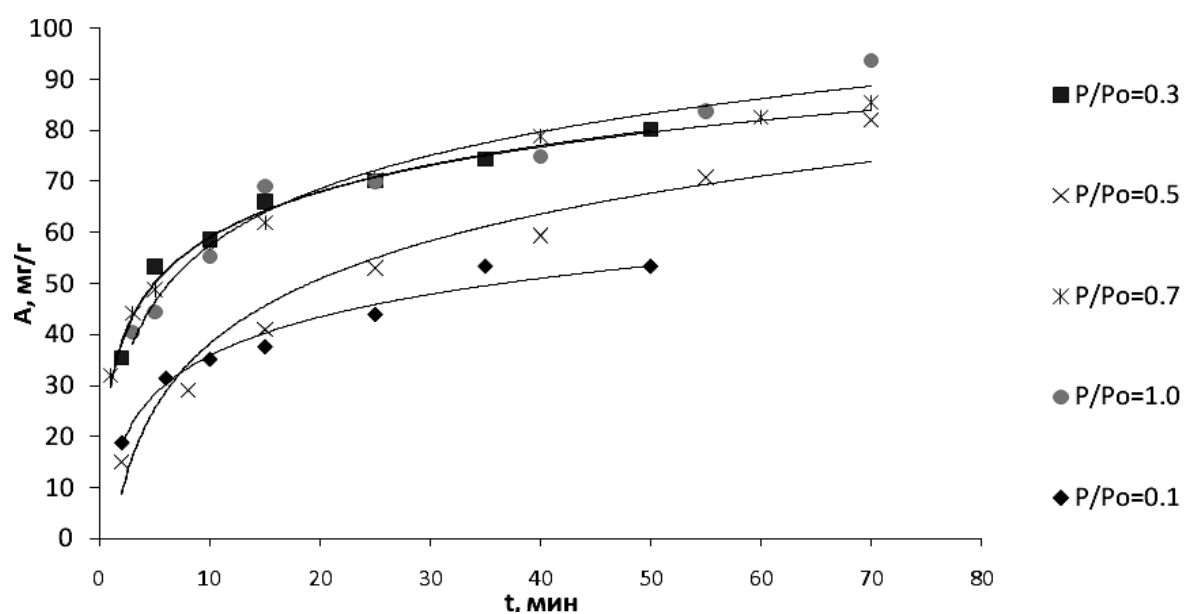

Рис. 4. Кинетика адсорбции бутанола на активном угле из скорлупы

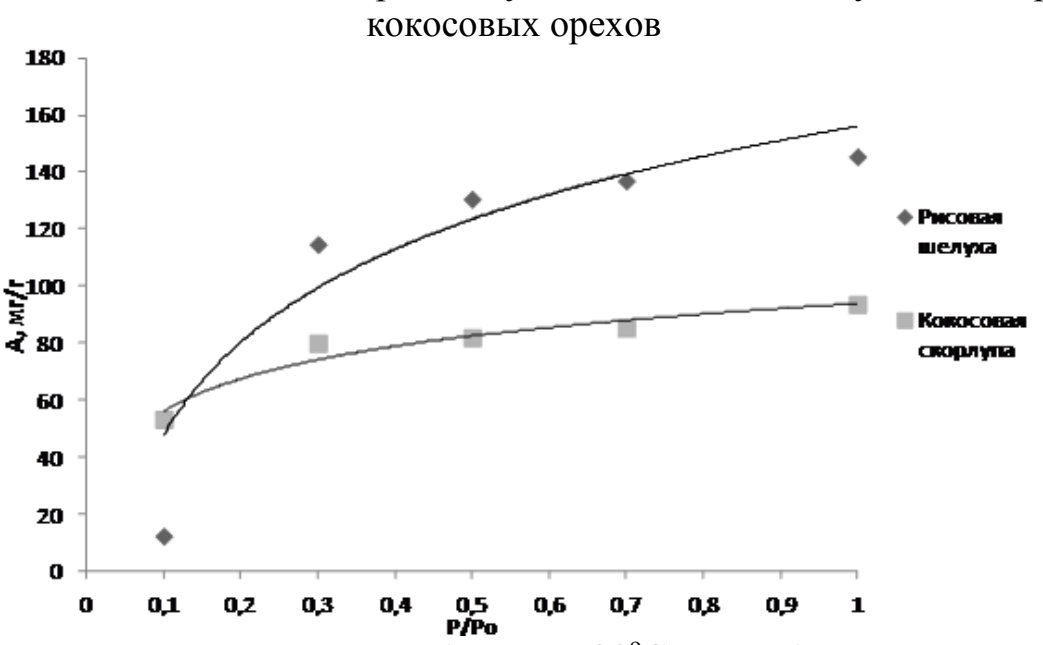

Рис. 5. Равновесие адсорбции при $20^{\circ} \mathrm{C}$ паров бутанола из его ПВС на активных углях из рисовой шелухи и кокосовой скорлупы

Конечно, эта оценка в большей мере качественная, поскольку различия в энергии адсорбции, а также неоднозначность ориентации (плоская или реберная) молекулы бензола на поверхности сорбентов могут сделать недостаточно корректными выводы, основанные на результатах только одного метода.

Следует отметить, что в работе [7] для интерпретации результатов адсорбционных измерений в рамках модели БЭТ была использована первая производная функции адсорбции $\mathrm{f}^{\prime}(\mathrm{a})$, причем ее величине, нормированной к значению емкости монослоя, был придан физический смысл адсорбционного потенциала. В настоящей работе для интерпретации результатов адсорбционных измерений используется модель Дубинина-Радушкевича, поэтому нормирование $\mathrm{f}^{\prime}(\mathrm{a})$ следует провести по отношению к объему микропор. В табл. 2 представлены результаты расчета первой производной функции адсорбции и ее величины, нормированной к значению объема микропор - $\mathrm{f}^{\prime}(\mathrm{a}) / \mathrm{V}_{\text {ми }}$, там же приведены результаты расчета величины $\mathrm{f}^{\prime}(\mathrm{a})$, нормированной к значению сорбционного объема - $\mathrm{f}^{\prime}(\mathrm{a}) /\left(\mathrm{V}_{\text {ми+ме }}\right)$. 
Таблица 2. Значения первой производной функции адсорбции

\begin{tabular}{|c|c|c|c|c|c|c|}
\hline \multirow{2}{*}{$\mathrm{p} / \mathrm{p}_{0}$} & \multicolumn{2}{|c|}{$\mathrm{f}^{\prime}(\mathrm{a})$} & \multicolumn{2}{c|}{$\mathrm{f}^{\prime}(\mathrm{a}) / \mathrm{V}_{\text {ми }}$} & \multicolumn{2}{c|}{$\mathrm{f}^{\prime}(\mathrm{a}) /\left(\mathrm{V}_{\text {ми }}\right.$ ме $)$} \\
\cline { 2 - 7 } & $\mathrm{KP}$ & $\mathrm{AУP}$ & $\mathrm{KP}$ & $\mathrm{AУP}$ & $\mathrm{KP}$ & $\mathrm{AУР}$ \\
\hline 0.001 & 4250 & 3370 & 61.6 & 43.5 & 49.9 & 31.5 \\
\hline 0.002 & 2830 & 2230 & 41.0 & 28.8 & 33.2 & 20.8 \\
\hline 0.003 & 1170 & 1012 & 17.0 & 13.1 & 13.7 & 9.45 \\
\hline 0.004 & 916 & 833 & 13.3 & 10.8 & 10.8 & 7.78 \\
\hline 0.005 & 573 & 588 & 8.30 & 7.60 & 6.73 & 5.49 \\
\hline 0.006 & 333 & 367 & 4.83 & 4.74 & 3.91 & 3.43 \\
\hline 0.02 & 146 & 159 & 2.12 & 2.05 & 1.71 & 1.48 \\
\hline 0.05 & 70.8 & 78.4 & 1.03 & 1.02 & 0.831 & 0.732 \\
\hline 0.10 & 32.7 & 45.1 & 0.474 & 0.583 & 0.384 & 0.422 \\
\hline 0.20 & 21.3 & 33.3 & 0.309 & 0.430 & 0.250 & 0.311 \\
\hline 0.30 & 16.7 & 29.4 & 0.242 & 0.380 & 0.196 & 0.275 \\
\hline 0.40 & 14.1 & 20.1 & 0.204 & 0.260 & 0.165 & 0.188 \\
\hline 0.50 & 10.2 & 15.1 & 0.148 & 0.195 & 0.120 & 0.141 \\
\hline 0.60 & 10.5 & 10.9 & 0.152 & 0.141 & 0.123 & 0.102 \\
\hline 0.70 & 10.2 & 10.4 & 0.148 & 0.134 & 0.120 & 0.097 \\
\hline 0.80 & 10.7 & 10.3 & 0.155 & 0.133 & 0.126 & 0.096 \\
\hline 0.85 & 12.0 & 15.7 & 0.174 & 0.203 & 0.141 & 0.147 \\
\hline 0.90 & 17.3 & 22.7 & 0.251 & 0.293 & 0.203 & 0.212 \\
\hline 0.92 & 25.3 & 32.0 & 0.367 & 0.413 & 0.297 & 0,299 \\
\hline 0.94 & 35.2 & 41.8 & 0.510 & 0.540 & 0.413 & 0.390 \\
\hline 0.96 & 52.2 & 56.7 & 0.757 & 0.733 & 0.613 & 0.529 \\
\hline 0.97 & 72,2 & 83,3 & 1.05 & 1.08 & 0.847 & 0.778 \\
\hline 0.98 & 107.1 & 196.7 & 1.55 & 2.54 & 1.26 & 1.84 \\
\hline
\end{tabular}

Величина $\mathrm{f}^{\prime}(\mathrm{a})$ для обоих образцов снижается до области средних заполнений, затем после некоторой стабилизации возрастает. При этом при сверхмалых заполнениях первая производная функции адсорбции АУР заметно ниже таковой КР. Ниже приведены результаты расчета расхождения ( $\Delta$, \%) между величинами $\mathrm{f}^{\prime}(\mathrm{a})$ и $\mathrm{f}^{\prime}(\mathrm{a}) / \mathrm{V}_{\text {ми }}$ :

\begin{tabular}{|c|c|c|c|c|c|c|c|c|c|}
\hline $\mathrm{p} / \mathrm{p}_{0}$ & 0.001 & 0.002 & 0.003 & 0.004 & 0.005 & 0.006 & 0.02 & 0.05 & 0.10 \\
\hline$\Delta\left[\mathrm{f}^{\prime}(\mathrm{a})\right]$ & 26.1 & 26.9 & 15.6 & 9.96 & $-2,55$ & -9.26 & -8.18 & -9.69 & -27.5 \\
\hline$\Delta\left[\mathrm{f}^{\prime}(\mathrm{a}) / \mathrm{V}_{\text {ми }}\right]$ & 41.6 & 42.4 & 29.8 & 23.1 & 9.21 & 1.90 & 3.41 & 0.98 & -18.7 \\
\hline
\end{tabular}

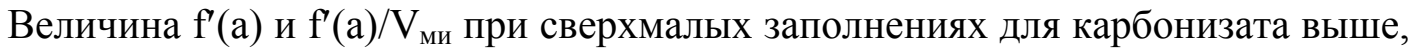
чем для активного угля. Этот факт можно объяснить тем обстоятельством, что в случае КР в адсорбционном процессе участвуют обладающие более высоким адсорбционным потенциалом ультрамикропоры меньшего размера (см. рис. 2а), чем микропоры АУР.

\section{Заключение}

Показано, что при парогазовой активации карбонизата рисовой шелухи первичная пористость карбонизата, представленная ультрамикропорами с максимумом при $\sim 0.68$ нм, супермикропорами с максимумом $\sim 1.1$ нм и мезопорами с максимумом $\sim 3$ нм, в процессе его парогазовой активации развивается в направлении радиального выгорания ультрамикропор со смещением максимума распределения в сторону увеличения размеров, полного выгорания супермикропор и двукратного увеличения объема мезопор. Парогазовая активация карбонизата рисовой шелухи приво- 
дит к росту энергии адсорбции азота при 77К с 20.8 до 27.5 кДж/моль. Сделано предположение о наличии в карбонизате кислотных центров, которые в процессе активации на $80 \%$ экранируются продуктами термодеструкции основы. Выявлены кинетические и равновесные преимущества активного угля из рисовой шелухи по отношению к активному углю из скорлупы кокосового ореха при извлечении этими адсорбентами бутанола из смесей его паров с воздухом.

\section{Список литературы}

1. Вин Мьинт Со, Тху Аунг Си, Клушин В.Н. и др. // Сорбционные $и$ хроматографические проиессы. 2016. Т. 16. № 5. C. 280-284.

2. Фенелонов В.Б. Пармон В.Н. Адсорбционные методы измерения общей и парциальной поверхности гетерогенных катализаторов и носителей (современное состояние и тенденции развития). В сб.: Промышленный катализ в лекциях. Под ред. проф. А.С. Носкова. М. Калвис, 2006. С. 77-119.

3. Кельцев Н.В. Основы адсорбционной техники. 2-е изд. перераб. и доп. М. Химия. 1984. $592 \mathrm{c}$.

\section{References}

1. Win Myint Saw, Thu Aung Si, Klushin V.N. et al., Sorbtsionnye i khromatograficheskie protsessy, 2016, Vol. 16, No 5, pp. 280-284.

2. Fenelonov V.B. Parmon V.N. Adsorbcionnye metody izmerenija obshhej i parcial'noj poverhnosti geterogennyh katalizatorov $i$ nositelej (sovremennoe sostojanie $i$ tendencii razvitija). V sb.: Promyshlennyj kataliz v lekcijah. Pod red. prof. A.S. Noskova. M., Kalvis publ., 2006, pp. 77-119.

3. Kel'cev N.V. Osnovy adsorbcionnoj tehniki. 2-e izd. pererab. i dop. M., Himija publ. 1984, $592 \mathrm{p}$.

Тху Аунг Си - аспирант кафедры промышленной экологии РХТУ им. Д.И. Менделеева, Москва

Вин Мьинт Со - аспирант кафедры промышленной экологии РХТУ им. Д.И. Менделеева, Москва

Клушин Виталий Николаевич - д.т.н., профессор, профессор кафедры промышленной экологии РХТУ им. Д.И. Менделеева, Москва

Нистратов Алексей Викторович - к.т.н., доцент кафедры промышленной экологии РХТУ им. Д.И. Менделеева, Москва
4. Кельцев Н.В. Основы адсорбционной техники. М. Химия. $1976.511 \mathrm{c.}$

5. Грег С., Синг К. Адсорбция, удельная поверхность, пористость: пер. с англ., 2-е изд. М. Мир. 1984. 306 с.

6. Брукхофф Й.К.П., Линсен Б.Г. Глава 1. Исследования текстуры адсорбентов и катализаторов. В кн.: Строение и свойства адсорбентов и катализаторов. М. Мир 1973. С. 23-81.

7. Сотникова Н.И. Дисс. канд. хим. наук. M. 2013, 16 c.

4. Kel'cev N.V. Osnovy adsorbcionnoj tehniki. M., Himija, 1976, 511 p.

5. Russ. ed. Greg S., Sing K. Adsorbcija, udel'naja poverhnost', poristost', 2-nd ed. Moscow, Mir publ., 1984, 306 p.

6. Brukhoff J.K.P., Linsen B.G. Chapter 1. Issledovanija tekstury adsorbentov $i$ katalizatorov. V kn.: Stroenie i svojstva adsorbentov i katalizatorov. M., Mir publ.,1973, pp. 23-81.

7. Sotnikova N.I. Diss. kand. him. nauk. Moscow, 2013, 16 p.

Thu Aung Si - post-graduate student of Department of industrial ecology, MUCTR, Moscow

Win Myint Saw - post-graduate student of Department of industrial ecology, MUCTR, Moscow

Klushin Vitaly Nickolaevich - Doctor of Technical Science, professor, professor of Department of industrial ecology, MUCTR, Moscow

Nistratov Alexey Viktorovich - candidate of technical sciences, associate professor of Department of industrial ecology, MUCTR, Moscow

$\boldsymbol{T} x y$ Аунг $C u$ и др. / Сорбционные и хроматографические процессы. 2017. Т. 17. № 1 
Киреев Сергей Георгиевич - к.Х.н., ведущий научный сотрудник, ОАО ЭНПО «Неорганика», Электросталь

Мухин Виктор Михайлович- д.т.н., профессор, начальник лаборатории в ОАО ЭНПО «Неорганика», Электросталь
Kireev Sergey Georgievich - candidate of chemical science, leading researcher, Open Joint-Stock Company NPO «Neorganika», Elektrostal

Mukhin Victor Mikhailovich - Doctor of Technical Science, professor, head of the laboratory, Open Joint-Stock Company NPO «Neorganika», Elektrostal 